\title{
Dysplastic Cerebellar Gangliocytoma
}

National Cancer Institute

\section{Source}

National Cancer Institute. Dysplastic Cerebellar Gangliocytoma. NCI Thesaurus. Code C8419.

A benign, WHO grade I cerebellar mass, which occurs in young adults and is composed of dysplastic ganglion cells. It is the major CNS manifestation of Cowden disease, an autosomal dominant condition that causes a variety of hamartomas and neoplasms. 